\title{
L'auto-incompatibilité chez les plantes à fleurs
}

\author{
Thierry Gaude, Sylvain Glémin, Didier Cabrillac, Agnès Mignot
}

Société Française
de Génétique
Président
Gérard Buttin, Institut Pasteur, Paris
Secrétaire général
Godeleine Faugeron, Institut Jacques
Monod, Paris
Trésorier
Michel Solignac, Université Paris Sud,
Orsay
Vice-présidents
Michel Solignac, Université Paris Sud,
Orsay
Pierre Thuriaux, CEA, Saclay
Autres membres du bureau
David Bouchez, Inra, Versailles
Alain Bucheton, Cnrs, Montpellier
Gabrielle Gendrel, Institut Curie,
Paris
Marie-Claude Hors-Cayla, Inserm,
Paris
Gérard Loison, Sanofi
Micheline Mirashi-Ahadou, Inserm,
Paris
Alain Nicolas, Institut Curie, Paris
Odile Ozier-Kalogeropoulos, Institut
Pasteur, Paris
Prière d'adresser toute correspondance au
Secrétaire général, Godeleine Faugeron,
Institut Jacques Monod, Tour 43, 2, pla-
ce Jussieu, 7525I Paris Cedex 05, France.
Comité de rédaction
A. Bernheim
M. Bolotin-Fukuhara
M. Fellous
J. Génermont
M.C. Hors-Cayla
R. Motta
A. Nicolas
M. Solignac
S. Sommer
P. Thuriaux
D. de Vienne

$m / s n^{\circ} 6-7$, vol. 17 , juin-juillel 2001
La reproduction sexuée des plantes à fleurs implique une série d'étapes de reconnaissance entre le grain de pollen, qui transporte les gamètes mâles, et le pistil, qui renferme les gamètes femelles. Au cours de la pollinisation, le grain de pollen est amené au contact du stigmate, surface réceptrice du pistil, par le vent, l'eau ou des vecteurs animaux. Le stigmate possède des capacités de discrimination qui s'exercent à l'encontre du pollen d'une autre espèce (isolement interspécifique), mais souvent aussi du pollen provenant de la même plante (réaction d'auto-incompatibilité). Chez la plupart des angiospermes, les possibilités d'autofécondation sont importantes puisque $96 \%$ des espèces possèdent simultanément sur un même pied des organes mâles et femelles et que, parmi elles, $75 \%$ ont les deux organes présents dans la même structure, la fleur hermaphrodite. Cette proximité des organes mâles et femelles entraîne un risque important de fécondation entre les gamètes produits par le même individu, ou autofécondation. L'autofécondation induit une consanguinité élevée qui peut s'avérer néfaste. Au cours de l'évolution, des systèmes qui assurent la reconnaissance et le rejet du pollen en provenance du même individu ont été sélectionnés. Ces mécanismes, regroupés sous le terme d'auto-incompatibilité, s'opposent ainsi à l'autofécondation et évitent ou limitent la consanguinité.

La signification évolutive de ces systèmes d'auto-incompatibilité est considérable, comme en atteste le pourcentage élevé (plus de $50 \%$ des espèces) d'angiospermes qui possè- dent de tels systèmes, et le fait que plusieurs systèmes d'auto-incompatibilité soient apparus de manière indépendante au cours de l'évolution. Il est généralement admis que la sélection de ces systèmes serait à l'origine du rapide succès évolutif des plantes à fleurs et de leur position dominante dans la flore mondiale [1].

Dans la plupart des cas, l'auto-incompatibilité est sous le contrôle d'un seul locus multiallélique, appelé locus $S$ ( $S$ pour self-incompatibility; [2]). Les analyses de génétique classique ont conduit à définir deux types de systèmes d'auto-incompatibilité selon l'origine génétique du caractère d'auto-incompatibilité porté par le pollen (figure 1). Quand le phénotype d'incompatibilité du pollen est déterminé par son propre génotype $S$ haploïde, le système est défini comme gamétophytique. Quand le phénotype d'incompatibilité du pollen est déterminé par le génotype $S$ diploide de la plante mère (le sporophyte), le système est défini comme sporophytique. Dans tous les cas, le rejet du pollen se produit lorsque le même allèle $S$ est exprimé à la fois par le pollen et le pistil. Dans les systèmes gamétophytiques, il n'existe pas de relations de dominance/récessivité entre allèles $S$. Il en résulte une hétérozygotie de tous les individus à ce locus, un échec systématique de l'autofécondation et une impossibilité de pollinisation d'une plante par un pollen qui porterait l'un de ses deux allèles. En revanche, des interactions entre allèles $S$ peuvent se produire dans le système sporophytique et, par conséquent, la production de graines homozygotes pour un 


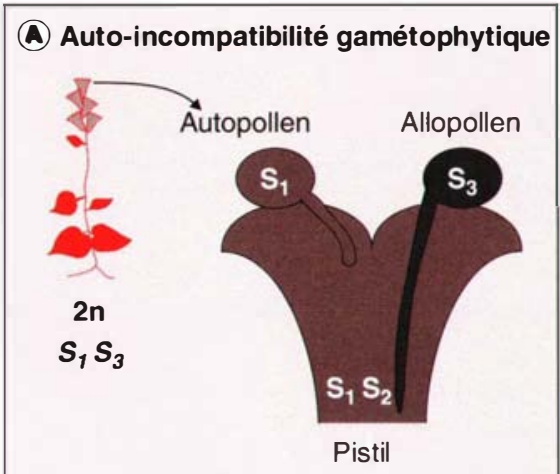

(B) Auto-incompatibilité sporophytique

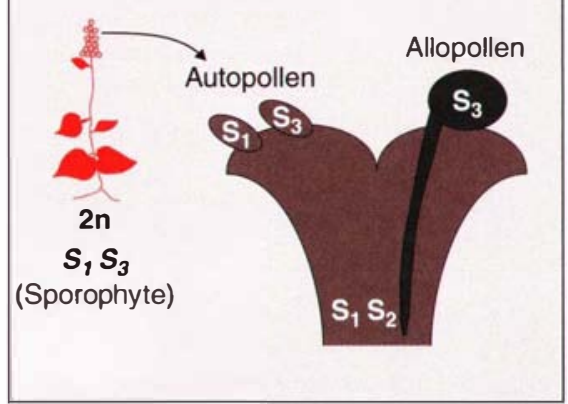

Figure 1. Systèmes d'auto-incompatibilité. A. Auto-incompatibilité gamétophytique: Le comportement du grain de pollen est déterminé par son propre génome haploïde. Les grains de pollen portant la même spécificité allélique $\mathrm{S}\left(\mathrm{S}_{1}\right.$ dans notre exemple) que l'une de celles exprimées par le pistil diploïde $\left(\mathrm{S}_{1} \mathrm{~S}_{3}\right)$ sont rejetés. Les tubes polliniques incompatibles sont généralement arrêtés dans le style. B. Auto-incompatibilité sporophytique: le comportement du grain de pollen est déterminé par le génome diploïde de la plante mère du pollen $\left(\mathrm{S}_{1} \mathrm{~S}_{3}\right)$. Dans notre exemple, les grains de pollen $\mathrm{S}_{3}$ issus de la plante $\mathrm{S}_{1} \mathrm{~S}_{3}$ sont rejetés car l'allèle $\mathrm{S}_{1}$ est exprimé à la fois par la plante donneuse de pollen et par le pistil $\mathrm{S}_{1} \mathrm{~S}_{2}$. La réponse d'auto-incompatibilité se produit seulement si $\mathrm{S}_{1}$ est dominant sur $\mathrm{S}_{3}$ ou codominant dans le pollen et si $\mathrm{S}_{1}$ est dominant sur $\mathrm{S}_{2}$ ou codominant dans le pistil. Les grains de pollen incompatibles ne germent pas ou s'ils germent, la croissance du tube pollinique sera arrêtée à la surface du stigmate.

allèle $S$ récessif est possible chez les plantes possédant ce système. Quel que soit le système d'auto-incompatibi- fonctionnel, le locus $S$ contienne au moins deux unités de transcription, la première codant le déterminant mâle, la seconde le déterminant femelle, l'interaction entre les deux conduisant à la réponse d'auto-incompatibilité (figure 2).

Il est intéressant de noter que des espèces autocompatibles existent au sein de familles où l'auto-incompatibilité est généralement la règle. Par exemple, chez les Brassicacées, Arabi dopsis thaliana est parfaitement autocompatible. En raison de la complexité des mécanismes d'autoincompatibilité, il est probable que les espèces autocompatibles ont évolué à partir d'espèces auto-incompatibles, par des mutations ou des délétions affectant les gènes au locus $S$, ou des gènes contrôlant leur expression, ou bien encore des gènes impliqués dans l'établissement de la réponse d'auto-incompatibilité mais situés hors du locus $S$. Cette hypothèse a récemment été confortée par des études comparatives de la région contenant le locus $S$ chez deux espèces auto-incompatibles, Brassica rapa (syn. campestris) et Arabidopsis lyrata, et chez l'espèce autocompatible Arabidopsis thaliana [3, 4].

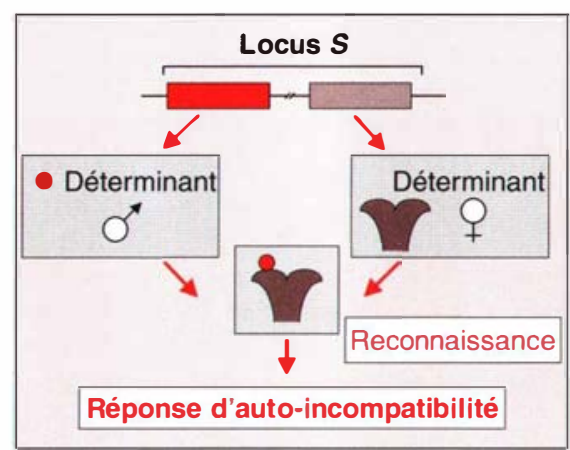

Figure 2. Génétique de la réponse d'auto-incompatibilité. Le locus S contient au moins deux gènes, I'un (rectangle rouge) codant le déterminant mâle porté par le pollen, et l'autre (rectangle bistre) codant le déterminant femelle exprimé par le pistil. La réponse d'auto-incompatibilité se produit lorsque les déterminants mâle et femelle sont issus du même locus S. Le pollen est représenté par un cercle rouge et le pistil est coloré en bistre.
Nous présentons d'abord les aspects moléculaires de la réponse d'autoincompatibilité établis à partir de travaux récents réalisés sur quelques espèces modèles illustrant les systèmes gamétophytiques et sporophytiques d'auto-incompatibilité, contrôlés par un locus $S$ unique et plus particulièrement dans le modèle Brassica (auto-incompatibilité sporophytique), qui a fait l'objet d'avancées spectaculaires ces deux dernières années. Puis nous abordons les aspects évolutifs des systèmes d'auto-incompatibilité, qui se caractérisent par un formidable polymorphisme des gènes recrutés au cours de l'évolution pour répondre à la question biologique du contrôle de la consanguinité chez les plantes à fleurs.

\section{Systèmes d'auto-incompatibilité gamétophytiques}

Les systèmes gamétophytiques d'auto-incompatibilité sont les plus communs et ont été décrits chez plus de 60 familles incluant les Solanacées, les Liliacées, les Rosacées et les Papavéracées. Le rejet de l'autopollen se traduit par l'arrêt de la croissance du tube pollinique qui transporte les gamètes mâles vers le sac embryonnaire contenant les gamètes femelles. Cet arrêt se produit généralement dans le tissu de transmission du style, qui constitue un tissu reliant le stigmate, zone de perception des pollens, à l'ovaire, lieu où se déroule la double fécondation caractéristique des plantes à fleurs. Cependant, chez le coquelicot (Papaver rhoeas, Papavéracée), la croissance du tube pollinique est interrompue plus tôt, à la surface même du stigmate. La plupart des travaux moléculaires ont été entrepris chez deux espèces de Solanacées, Nicotiana alata et Petunia inflata, et le coquelicot, Papaver rhoeas.

\section{Solanacées et RNase $S$}

Dans les systèmes gamétophytiques d'auto-incompatibilité, le premier gène situé au locus $S$ a été identifié 
dans le milieu des années 1980 chez $N$. alata [5]. Ce gène est exprimé spécifiquement dans le pistil et code une glycoprotéine qui est abondamment produite, pouvant représenter jusqu'à plusieurs microgrammes par pistil. Elle est sécrétée dans l'espace extracellulaire, principalement dans le stigmate et dans le tissu de transmission du style. L'analyse des séquences de différentes formes alléliques $S$ de cette glycoprotéine a révélé l'existence d'une homologie significative avec les ribonucléases (RNases) extracellulaires fongiques $\mathrm{T} 2$ et $\mathrm{Rh}$, isolées respectivement d'Aspergillus oryzae et de Rhizopus niveus [6]. Les glycoprotéines $S$ possèdent effectivement une activité ribonucléase et ces protéines sont maintenant nommées RNases $S$. Il est intéressant de noter que d'autres systèmes gamétophytiques reposent également sur l'expression de RNases $S$ stylaires chez les Rosacées (cerisier, poirier, pommier) et les Scrophulariacées (muflier) [7-10]. Une caractéristique commune à ces RNases $S$ est que leur structure se compose d'une alternance de régions variables et conservées, avec la présence d'une (Rosacées [9]) ou de deux (Solanacées et Scrophulariacées [10, 11]) régions hypervariables (HV).

Les RNases $S$ sont hautement polymorphes. Par exemple, chez les Solanacées, l'identité en acides aminés entre différentes RNases $S$ s'échelonne de 38 à $98 \%$. Ce niveau de polymorphisme est inhabituel pour la plupart des gènes. Toutefois, une telle diversité de séquence est attendue pour des produits de gènes qui sont impliqués dans des mécanismes de reconnaissance du soi [12]. L'apparition d'une nouvelle spécificité allélique $S$ dans une population est favoriséc, car un pollen exprimant ce nouvel allèle $S$ aura une forte probabilité de rencontrer un stigmate portant un allèle $S$ différent (voir plus loin).

L'implication directe des RNases $S$ dans la réponse de rejet de l'autopollen a été démontrée par des expériences de transgenèse réalisées chez $N$. alata $[13,14]$ et $P$. inflata $[11,15]$. Chez Petunia, l'invalidation du gène RNase $S$ par une stratégie antisens, et $\mathrm{m} / \mathrm{s} n^{\circ} 6-7$, vol. 17 , juin-juillet 2001 l'acquisition d'une nouvelle spécificité allélique $S$ par une stratégie sens, a montré que les RNases $S$ sont suffisantes pour assurer la reconnaissance et le rejet de l'autopollen par le pistil [15]. De plus, l'activité RNase des glycoprotéines $S$ est nécessaire pour le rejet de l'autopollen. En effet, des plantes transgéniques exprimant une forme mutée de la glycoprotéine $S_{3}$ privée de l'activité RNase, ne sont pas capables de rejeter les pollens $S_{3}$ [16]. L'origine de la spécificité allélique $S$ a été recherchée; elle pourrait résider dans les chaînes glycosylées des RNases $S$ et/ou dans les régions hypervariables des séquences polypeptidiques. Le rôle de la partie glycosylée a été examiné en exprimant des protéines $S_{3}$ mutées non glycosylées chez des plantes transgéniques ne portant pas l'allèle $S_{3}$. Ces plantes produisent un niveau normal de la forme non glycosylée de la RNase $S_{3}$ et sont encore capables de rejeter les pollens $S_{3}$. Les chaînes glycanes ne confèrent donc pas la spécificité allélique $S$ et ne sont pas nécessaires à la fonction des RNases $S$ dans la reconnaissance et le rejet de l'autopollen [17]. Afin de déterminer le rôle des régions $\mathrm{HV}$, des RNases $S$ chimères composées de la chaîne polypeptidique de la RNase $S_{3}$, mais où les régions $\mathrm{HV}$ ont été remplacées par celles de la RNase $S_{l}$, ont été construites. Les plantes transgéniques exprimant ces RNases chimères perdent la capacité de rejeter le pollen $S_{3}$ mais n'acquièrent pas l'aptitude à rejeter le pollen $S_{1}$ [11]. Ce résultat suggère que les régions HV des protéines $S$ sont nécessaires mais pas suffisantes pour l'établissement de la spécificité allélique $S$. Cependant, une approche similaire réalisée chez une autre Solanacée, Solanum chacoense, a donné des résultats contradictoires [18, 19]. Chez cette espèce, les RNases $S_{11}$ et $S_{13}$ ne diffèrent que par quatre résidus acide aminé localisés dans les régions HV. Des plantes transformées avec des gènes chimères correspondant à la RNase $S_{l l}$ dont les quatre acides aminés des régions HV ont été remplacés par ceux de la RNase $S_{13}$, présentent un phénotype $S_{13}$. Ainsi, chez S. chacoense, il apparaît que les régions $\mathrm{HV}$ sont capables à elles seules de déterminer la spécificité allélique $S$. Il reste à vérifier si ce résultat peut s'appliquer à d'autres espèces où l'auto-incompatibilité est contrôlée par des RNases $S$.

Dans toutes les expériences de transgenèse réalisées sur la RNase $S$ stylaire, seul le phénotype d'auto-incompatibilité du pistil est affecté, alors que celui du pollen reste inchangé. Ces résultats indiquent que le composant mâle de la réponse d'autoincompatibilité n'est pas la RNase $S$ et accrédite l'hypothèse que les molécules $S$ du pollen et du pistil sont codées par deux gènes différents situés au locus $S$. Les nombreuses tentatives pour isoler le déterminant mâle de la réponse d'auto-incompatibilité sont restées infructueuses.

Chez les Solanacées, deux hypothèses ont été avancées pour expliquer la base moléculaire du rejet de l'autopollen, toutes deux reposant sur un effet cytotoxique des RNases $S$ [11]. Les RNases $S$, présentes dans l'espace extracellulaire du tissu de transmission du style, rentreraient dans le tube pollinique et hydrolyseraient les ARN ribosomiques et messagers, bloquant ainsi la synthèse protéique et par conséquent la croissance du tube pollinique [11]. La première hypothèse suppose que le déterminant $S$ pollinique est un récepteur présent à la surface du tube pollinique (dans la paroi ou la membrane plasmique). Ce récepteur permettrait une reconnaissance spécifique d'allèle et la translocation des RNases $S$ stylaires à l'intérieur du tube pollinique. Dans ce modèle "récepteur", seule la RNase $S$ stylaire de même allèle que l'allèle $S$ porté par le pollen entrerait dans le tube pollinique et inhiberait sa croissance. I a seconde hypothèse suppose que le déterminant $S$ du pollen est un inhibiteur cytosolique des RNases $S$ qui inactiverait toutes les RNases $S$, excepté celle qui a la même spécificité que le pollen. Dans ce modèle «inhibiteur», les RNases $S$ présentes dans le style entreraient dans le tube pollinique indépendamment de leur spécificité allélique, mais seule la RNase $S$ reconnue comme "soi " à l'intérieur du tube pollinique ne serait pas inhibée, et 
ainsi pourrait dégrader l'ARN du pollen. Une analyse en microscopie électronique reposant sur l'utilisation d'anticorps spécifiques de RNases $S$ chez $S$. chacoense a permis récemment de vérifier que l'entrée des RNases $S$ dans le tube pollinique incompatible n'était pas sélective [20]. Cette observation soutient fortement l'idée que le déterminant $S$ du pollen serait un inhibiteur des RNases $S$ chez les Solanacées.

\section{Papavéracées et glycoprotéines S}

Chez le coquelicot (Papaver rhoeas), les protéines $S$ stigmatiques sont également des glycoprotéines sécrétées dans l'espace extracellulaire, mais elles ne possèdent pas d'activité RNase, ni aucune autre activité catalytique connue [21]. Cependant, en utilisant un test de germination des pollens in vitro, ces glycoprotéines $S$ stigmatiques sont capables d'inhiber la croissance des tubes polliniques d'une manière spécifique de l'allèle $S$ [21]. De plus, les glycoprotéines $S$ interagissent avec une protéine de la membrane plasmique des pollens, appelée SBP (pour S binding protein), mais indépendamment de la nature de l'allèle $S$ [22]. Pour rendre compte de la spécificité de reconnaissance entre les déterminants mâle et femelle de la réponse d'auto-incompatibilité, on a supposé que la glycoprotéine $S$ stigmatique et la protéine pollinique SBP interagissent de manière spécifique de l'allèle $S$ avec un troisième composé codé par un gène au locus $S$.

Si la nature du composant $S$ mâle reste encore inconnue à ce jour, il existe de nombreuses informations sur les événements liés à la transduction du signal qui se produisent dans le pollen après la réponse initiale de reconnaissance [23]. Quand les tubes polliniques en croissance dans le milieu de germination sont mis en présence d'une glycoprotéine $S$ correspondant au même allèle $S$ que celui porté par le pollen, on observe dans les secondes qui suivent une augmentation transitoire de la concentration en calcium dans le tube pollinique, suivie de la phos- d'une protéine pollinique de 26 kDa, puis de la phosphorylation indépendante du calcium d'une protéine pollinique de $68 \mathrm{kDa}$. Bien que l'on ne connaisse pas le mécanisme d'action des phosphorylations dans l'arrêt de croissance du tube pollinique, il est intéressant de noter que la germination des pollens en présence de profiline peut aussi affecter le niveau de phosphorylation de la protéine pollinique de $26 \mathrm{kDa}$ [24]. La profiline est connue pour moduler le cytosquelette d'actine, mais elle pourrait également jouer un rôle en modifiant la croissance du tube pollinique via des interactions avec des protéines kinases ou leurs substrats.

\section{Système d'auto-incompatibilité sporophytique chez les Brassicacées}

\section{Le locus S des choux}

Bien que les systèmes d'auto-incompatibilité sporophytiques soient moins répandus que les systèmes gamétophytiques, ils touchent des familles généralement plus évoluées telles que les Caryophylacées, les Astéracées et les Brassicacées. La plupart des études sur les aspects moléculaires de l'auto-incompatibilité sporophytique portent sur cette dernière.

La génétique de l'auto-incompatibilité chez les Brassicacées a été initiée dans les années 50 par Bateman [25]. Chez les espèces auto-incompatibles de cette famille, les tubes polliniques ne se développent pas correctement sur les stigmates qui expriment le même allèle $S$ que le pollen. Le rejet résulte d'un blocage ou d'un arrêt rapide de la croissance du tube pollinique à la surface du stigmate. Il a cependant été possible d'obtenir expérimentalement des collections d'individus homozygotes pour divers allèles $S$ en pratiquant une autopollinisation des boutons floraux immatures, avant que le stigmate n'acquière sa capacité de rejeter le pollen. Le locus $S$ est hautement polymorphe dans le genre Brassica et l'on a établi l'existence de plus de 60 allèles chez le chou ( $B$. oleracea
[2]). Les études moléculaires récentes ont révélé une structure fort complexe pour ce locus qui s'étend sur plusieurs dizaines de kilobases et contient plusieurs gènes dont les allèles coségrègent avec le phénotype d'auto-incompatibilité [26-29]. Par analogie avec le complexe majeur d'histocompatibilité des mammifères, les phases alléliques pour la série des gènes exprimés au locus $S$ ont été appelées haplotypes [30]. Le séquençage de cette région très riche en gènes a révélé chez le navet (B. rapa) l'existence de 14 unités de transcription dans $76 \mathrm{kpb}$, soit une unité toutes les 5,4 kpb [29]. Parmi ces différents gènes localisés au locus $S$, trois ont fait l'objet d'une attention particulière car on pense qu'ils peuvent être impliqués dans la reconnaissance entre le pollen et le stigmate. Deux d'entre eux, SLG (S locus glycoprotein [31]) et SRK ( $S$ locus receptor kinase [32]), sont spécifiquement exprimés dans le stigmate, le troisième, SCR (S locus cysteine rich [33]), l'étant seulement dans les anthères et le pollen.

\section{Le déterminant femelle de la réponse d'auto-incompatibilité}

Comme l'accumulation des produits (transcrits et protéines) des gènes $S L G$ et $S R K$ coïncident avec l'acquisition de l'auto-incompatibilité au cours de la maturation du stigmate, ces deux gènes ont été considérés comme des candidats potentiels pour la composante femelle de la reconnaissance entre le pollen et le stigmate $[32,34]$. Le gène $S L G$, qui fut le premier gène identifié sur un locus $S$, code une glycoprotéine sécrétée dans la paroi cellulaire des papilles stigmatiques [31]. Il est généralement dépourvu d'introns, à l'exception des allèles de quelques haplotypes où un seul intron est présent. Dans le cas de l'allèle $S L G_{2}$ (correspondant à l'haplotype $S_{2}$ ), des transcrits alternatifs peuvent coder deux protéines SLG, une forme étant sécrétée, l'autre ancrée dans la membrane [35]. Pour l'haplotype $S_{15}$, deux gènes ont été caractérisés, SLGA et SLGB, tous deux interrompus par un unique intron [36]. Le premier code une 
forme soluble et une forme ancrée dans la membrane, tandis que le second code seulement des protéines solubles. Les haplotypes $S_{2}$ et $S_{5}$, qui montrent des similitudes avec $S_{15}$ en termes de séquence et de phénotype (ils déterminent une incompatibilité plus faible que les autres haplotypes $S$ et sont des allèles récessifs dans l'anthère), ne possèdent que l'un ou l'autre de ces deux gènes. Ces homologies de séquence et de phénotype se retrouvent pour d'autres haplotypes $S$ caractérisés chez le navet (B. rapa) ou le colza (B. napus) et ont conduit à définir deux classes d'haplotypes $S$ : la classe I, la plus abondante, exhibant généralement un caractère d'auto-incompatibilité fort, et la classe II, correspondant aux allèles $S$ récessifs dans l'anthère $\left(S_{2}, S_{5}\right.$ et $S_{15}$ chez $B$. oleracea).

Cependant le rôle du gène $S L G$ dans l'auto-incompatibilité a été sérieusement remis en cause récemment. En effet, des plantes où ce gène s'exprime très faiblement ou pas du tout, peuvent être auto-incompatibles tandis que des plantes qui l'expriment très fortement peuvent être autocompatibles [37-39]. De plus, l'analyse moléculaire des homozygotes pour $S_{18}$ et $S_{60}$ de $B$. oleracea a montré que ces haplotypes sont incapables de produire une SLG fonctionnelle en raison de l'existence de mutations dans la région codante du gène alors que leur phénotype d'auto-incompatibilité est parfaitement maintenu [40]. SIG ne semblant pas essentiel pour l'auto-incompatibilité chez Brassica, le rôle clé a été transféré à $S R K$. Ie gène $S R K$ code une protéine transmembranaire localisée dans le plasmalemme des papilles stigmatiques. SRK possède un domaine extracellulaire présentant une forte homologie avec SLG, une région transmembranaire unique et un domaine cytoplasmique à activité sérine-thréonine kinase [41-43]. Cette structure rappelle celle des récepteurs kinase des animaux et l'on suspecte que le domaine extracellulaire fonctionne comme région d'association à un ligand. L'interaction entre le ligand (le déterminant $S$ mâle) amené par le pollen et SRK déclencherait une cascade de signali- sation dans les papilles stigmatiques conduisant au rejet de l'autopollen.

L'implication de $S R K$ dans l'établissement de la réponse d'auto-incompatibilité a été attestée par l'analyse de variants autocompatibles chez le colza et le chou $[44,45]$. Ces variants (qui expriment par ailleurs des taux normaux de SLG) sont porteurs de mutations qui entraînent l'absence de transcrits $S R K$ ou ne donnent que des transcrits tronqués. La preuve définitive que $S R K$ est le déterminant de l'auto-incompatibilité au niveau du stigmate a été apportée grâce à des expériences de transgenèse. Takasaki et al. [46] ont montré, chez le navet, que des plantes auto-incompatibles d'haplotype $S_{60}$ acquièrent, après transformation par le gène $S R K_{28}$, la possibilité de rejeter le pollen $S_{28}$ en plus du pollen $S_{60}$. Dans cette analyse, le rôle potentiel de $S L G$ a été établi sur la base du phénotype de plantes transgéniques exprimant à la fois $S K R_{28}$ et $S L G_{28}$. Bien que l'expression de $S L G_{28}$ ne soit pas à elle seule suffisante pour conférer une nouvelle spécificité haplotypique aux plantes transgéniques, le rejet du pollen $S_{28}$ est renforcé chez les plantes exprimant à la fois le transgène $S R K_{28}$ et le transgène $S L G_{28}$. Ces résultats indiquent que SRK confère à lui seul la spécificité haplotypique $S$ au stigmate alors que SLG agit probablement pour assurer une manifestation complète de la réponse d'auto-incompatibilité.

\section{Composante mâle de la réponse d'auto-incompatibilité}

Plusieurs gènes du locus $S$ dont l'expression est spécifique des tissus mâles ont été considérés comme des candidats potentiels codant le déterminant mâle [27, 29, 47-49]. Cependant, ces candidats ont été écartés soit parce qu'ils étaient présents aussi bien dans des lignées compatibles qu'incompatibles, soit parce qu'ils ne présentaient pas un polymorphisme allélique dans différents haplotypes $S$, ou enfin parce qu'il n'existait aucune preuve directe de leur implication dans la réponse d'auto-incompatibilité. Stephenson et al. [50], utilisant un protocole de pollinisation contrôlée (bioessai), ont montré que les pro- téines tapissant les cavités de la paroi pollinique mélangées à des pollens compatibles pouvaient induire une réponse d'auto-incompatibilité sur le stigmate, spécifique de l'haplotype $S$. Le fractionnement de ces protéines a révélé que les molécules actives sont des protéines basiques de moins de $10 \mathrm{kDa}$. Cependant, ce n'est que très récemment que le déterminant mâle de l'auto-incompatibilité a été identifié. Par séquençage systématique de la région du locus $S$ appartenant à des haplotypes différents, un nouveau gène, spécifiquement exprimé dans les anthères a été isolé. Il s'agit de $S C R$ (S locus cysteine rich) qui code une nouvelle classe de peptides très polymorphes appartenant à la famille des PCP (pollen coat proteins) [33]. L'analyse des séquences polypeptidiques, déduites de 20 clones SCR, montre que les protéines SCR matures sont de petites protéines sécrétées $(5,7$ à $8,0 \mathrm{kDa}$ ), hydrophiles, basiques (point isoélectrique entre 7,8 et 9,3 ), et contenant 8 cystéines conservées [51]. L'étude de l'expression temporelle et spatiale du gène $S C R$ chez $B$. rapa a permis de détecter des transcrits dans les tissus sporophytiques de l'anthère à des stades jeunes de développement et dans le pollen à des stades tardifs [52]. La démonstration finale du rôle de SCR a été apportée par des expériences entraînant des pertes et des gains de fonction [33]. Un mutant autocompatible de $B$. oleracea obtenu après irradiation aux rayons $\gamma$ ne produit pas de transcrits SCR détectables et a perdu sa spécificité mâle tout en conservant sa spécificité femelle. Réciproquement, la transformation d'une lignée homozygote $S_{2} S_{2}$ de $B$. oleracea par un $\mathrm{ADNC} S C R_{6}$ a conduit à la production de pollen $S_{2}$ qui exprime le transgène $S_{C} R_{6}$ (en plus de son propre $S C R_{2}$ ), et qui est rejeté par les stigmates $S_{6} S_{6}$. Ces résultats démontrent que le gène $S C R$ est nécessaire et suffisant pour déterminer la spécificité d'auto-incompatibilité du pollen.

\section{Contrôle moléculaire de la réponse d'auto-incompatibilité chez le chou}

Les données présentées ci-dessus nous permettent de postuler que la protéine SCR est le ligand pollinique qui va 
activer le récepteur SRK stigmatique dans le cas d'une pollinisation autoincompatible. Les protéines SCR migrent probablement de la paroi pollinique à la membrane plasmique de la papille stigmatique directement en contact avec le grain de pollen. SCR se lierait au domaine extracellulaire de SRK, éventuellement avec la participation de SLG comme le suggèrent les travaux de Takasaki et al. [46]. Le gène $S R K$ code également une forme tronquée et soluble du récepteur qui correspond à son domaine extracellulaire, la protéine eSRK [53]. Cette forme soluble pourrait jouer un rôle régulateur en favorisant la liaison de SCR au récepteur intégral SRK ou, au contrai-

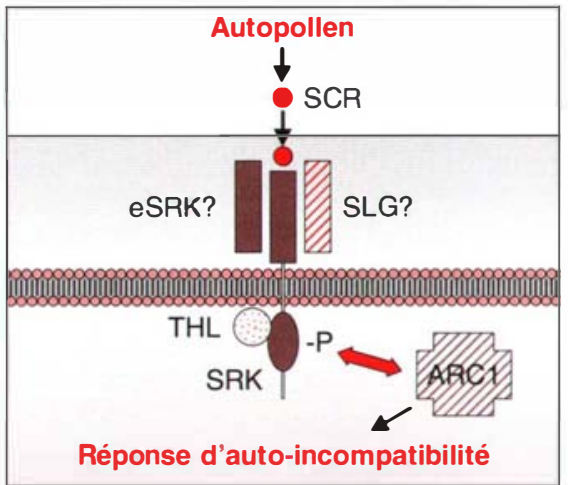

Figure 3. Modèle moléculaire de la réponse d'auto-incompatibilité chez Brassica. La protéine SCR portée par le pollen migre probablement à travers la paroi de la papille stigmatique pour atteindre la membrane plasmique. SCR interagirait avec le domaine extracellulaire du récepteur kinase SRK, éventuellement avec la participation des molécules solubles eSRK et SLG. À l'état basal, l'activité kinase de SRK est régulée négativement par des thiorédoxines (THL) stigmatiques. La fixation de SCR sur le complexe SRK lèverait l'inhibition des thiorédoxines et permettrait l'activation de SRK par autophosphorylation du récepteur. Le domaine kinase phosphorylé viendrait alors recruter des cibles cytosoliques qui seraient à l'origine de la transduction du signal conduisant à l'établissement de la réponse d'auto-incompatibilité. Une de ces cibles cytosoliques est la protéine $A R C 1$ qui agit comme un régulateur positif de la ré- re, en empêchant la liaison du ligand par compétition. Il est intéressant de noter que des formes solubles tronquées de récepteurs kinase ont été observées dans les voies de transduction du signal chez les animaux [54, 55]. Dans ce cas, la forme soluble inhibe la transduction du signal en se liant au ligand du récepteur transmembranaire. Un rôle semblable pourrait être attribué à eSRK chez Brassica.

L'étude des récepteurs kinase animaux a révélé que le mode général d'action de ces récepteurs se fait au travers de l'activation de leur domaine cytosolique, consécutivement à la liaison du ligand [56]. De façon assez surprenante, il a été observé que des protéines SRK intégrales exprimées dans des cellules d'insecte sont phosphorylées de manière constitutive, sans l'addition d'extraits de pollen ou de stigmate [43]. De plus, par des expériences de couplage chimique et par mesure de la vitesse de sédimentation sur gradients de saccharose, SRK n'est jamais détecté sous forme monomérique, mais est toujours associé à d'autres molécules SRK et/ou d'autres protéines stigmatiques [43]. Ces résultats suggèrent que la transduction du signal liée à la réponse d'auto-incompatibilité est dépendante de modifications apportées à un complexe SRK oligomérique.

Très récemment, Cabrillac et al. [57] ont montré que, contrairement à l'autophosphorylation constitutive de SRK observée en cellules d'insecte, in planta, SRK n'est pas phosphorylé à l'état basal. L'activation de SRK n'est observée qu'après une heure de pollinisation incompatible. A l'état basal, SRK est maintenu inactif par des enzymes solubles ubiquistes, des thiorédoxines, qui sont des oxydo-réductases participant au contrôle du potentiel redox intracellulaire. Ces mêmes auteurs ont également montré que les protéines de la paroi pollinique (et contenant par conséquent SCR) sont capables de lever l'inhibition des thiorédoxines et d'activer le récepteur SRK in vitro. Il est intéressant de souligner que la régulation des récepteurs kinase est essentielle pour le développement normal d'une cellule. En effet, ces récepteurs constituent de véritables interrup- teurs moléculaires qui, lorsqu'ils sont activés après perception d'un signal, déclenchent une cascade d'événements biochimiques conduisant à la réponse cellulaire (différenciation, croissance, division, mort...). A l'état basal, en absence de signal, ces récepteurs doivent être maintenus dans un état inactif pour éviter un développement cellulaire anarchique. Dans les systèmes animaux, une autre protéine ubiquiste, l'immunophiline FKBP12 (FK506-binding protein 12) inhibe l'autophosphorylation des récepteurs kinase $[58,59]$. Dans le cas des interactions pollen-pistil, il est probable qu'en absence de ce mécanisme de régulation thiorédoxine dépendant de SRK, la réaction de rejet du pollen serait toujours activée et les fleurs ne pourraient jamais être fécondées et produire de graines.

Ces données originales sur le mode de régulation de SRK nous permettent de proposer un nouveau modèle moléculaire de la réponse d'autoincompatibilité chez le chou (figure 3). Lors du dépôt du pollen incompatible sur la surface stigmatique, l'interaction de SCR avec le complexe oligomérique SRK conduirait à un changement de conformation du domaine kinase qui annihilerait l'inhibition des thiorédoxines. Ceci autoriserait l'autophosphorylation entre deux domaine kinase de SRK adjacents. Une fois phosphorylés, les domaines kinases recruteraient leurs cibles cytosoliques pour initier la cascade de phosphorylations/déphosphorylations responsable du rejet de l'autopollen par la papille stigmatique. Parmi les protéines cytosoliques des cellules stigmatiques, la protéine ARCl (arm repeat containing) peut se lier au domaine kinase phosphorylé de SRK [60]. En produisant des plantes transgéniques exprimant l'ARNm ARC1 en orientation antisens, Stone et al. [61] ont montré que la suppression des transcrits $A R C 1$ était corrélée à une baisse partielle de l'auto-incompatibilité chez $B$. napus. Ces résultats indiquent que la protéine ARCl est un des composants de la voie de transduction du signal initiée par SRK, et qu'elle agit comme un effecteur positif de SRK, conduisant au rejet du pollen auto-incompatible. 


\section{Évolution moléculaire des gènes d'auto-incompatibilité}

\section{Polymorphisme des allèles S}

Alors que les mécanismes de reconnaissance impliqués dans l'autoincompatibilité intéressent les biologistes cellulaires et moléculaires, les généticiens des populations et les évolutionnistes ont été attirés par l'extraordinaire polymorphisme des allèles $S$. En effet, les estimations du nombre d'allèles fonctionnellement différents dans les populations sont de l'ordre de 30 à 50, avec une variation de 12 à 193 [62], alors que pour des marqueurs moléculaires classiques le nombre d'allèles est beaucoup plus faible (en général inférieur à 10 pour les isozymes et à 20 pour les microsatellites). Les mécanismes de maintien de cette diversité

\section{Auto-incompatibilité et sélection fréquence-dépendante}

La sélection fréquence-dépendante est un type de sélection particulier où les coefficients de sélections des différents allèles varient en fonction de leur fréquence. Pour les allèles d'autoincompatibilité, la sélection se fait en faveur des allèles rares : un allèle rare est sélectionné positivement puisqu'il est rarement reconnu et donc rarement rejeté par réaction d'incompatibilité. Mais la sélection dépend également du nombre d'allèles déjà présent dans la population: plus il y a d'allèles dans la population moins l'avantage d'être rare est important puisque tous les autres allèles sont également présents en faible fréquence. Formellement, dans le cas d'un système d'auto-incompatibilité gamétophytique, le changement de fréquence d'un allèle en fréquence $x_{i}$ en une génération s'écrit : $\Delta x_{i}=\frac{x_{i}\left(x_{i} J\right)}{(1 \quad J)\left(\begin{array}{ll}1 & 2 J\end{array}\right)}$ où $J=\sum x_{i}$ est l'homozygotie attendue au locus $\mathrm{S}$ [63]. On définit alors le nombre efficace d'allèles, $n_{e}$, comme le nombre d'allèles qui donnerait la même homozygotie s'ils étaient tous en fréquence égale. Pour ces systèmes, le nombre efficace d'allèles est proche du nombre réel d'allèles. Par définition $n_{e}=\frac{1}{\mathrm{~J}}$, et on peut

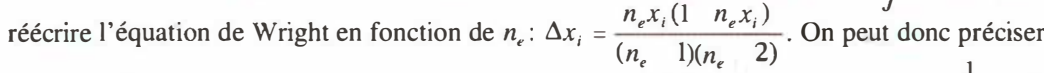
la notion d'allèles rare et fréquent. Un allèle est rare si sa fréquence est inférieure à $\frac{1}{n_{e}}$ et il sera alors sélectionné positivement $\left(\Delta x_{i}>0\right)$; un allèle est fréquent si sa fréquence est supérieure à $\frac{1}{\mathrm{n}_{\mathrm{e}}}$ et il sera alors sélectionné négativement $\left(\Delta \mathrm{x}_{\mathrm{i}}<0\right)$. Ce système tend donc vers un équilibre où tous les allèles ont la même fréquence : $\frac{1}{n}\left(\Delta x_{i}=0\right)$.

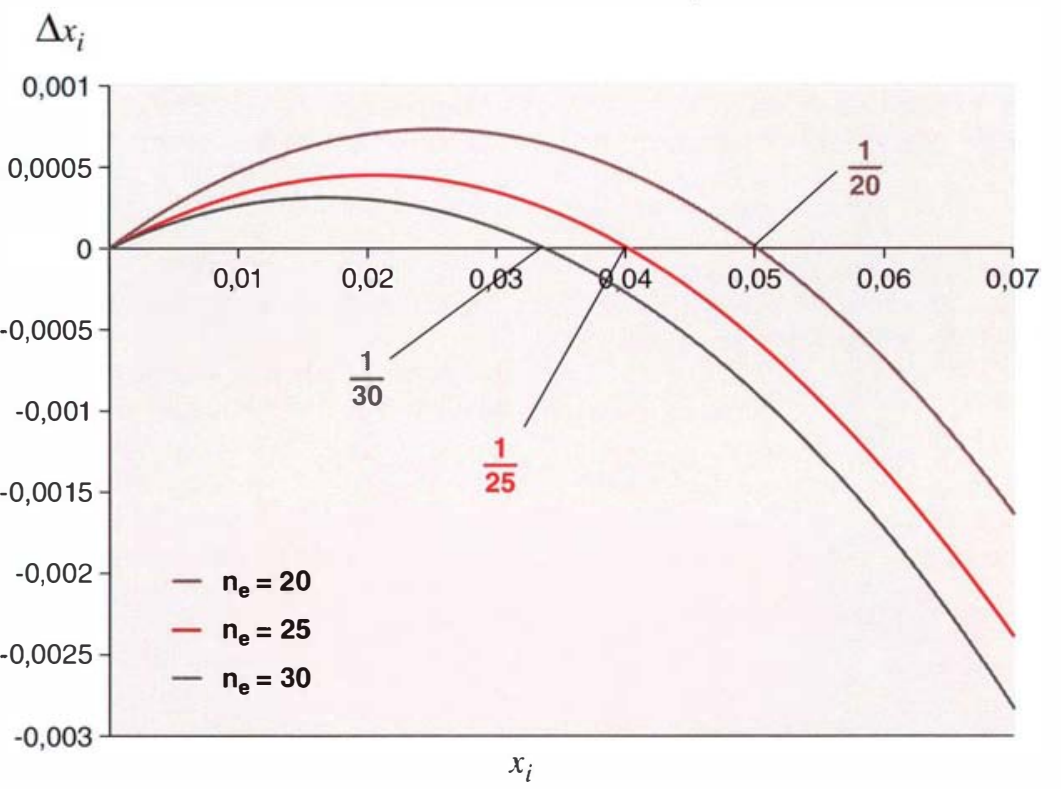

allélique sont bien élucidés [63] : les allèles rares sont avantagés lors de la pollinisation puisqu'ils ne sont que très rarement reconnus et donc rejetés par les stigmates qui les reçoivent. Cette sélection est dépendante de la fréquence puisqu'elle joue en faveur du rare et tend donc à favoriser chaque nouvel allèle apparu par mutation, jusqu'à ce qu'un équilibre soit atteint où tous les allèles sont présents en fréquence égale (encadré). Jusqu'à une date récente, seul le nombre d'allèles $S$ était accessible par des expériences de croisements. La caractérisation des gènes et le séquençage des allèles impliqués dans l'incompatibilité chez différentes espèces ont complètement renouvelé l'étude du polymorphisme de ces systèmes en permettant l'analyse de la diversité au niveau des séquences et l'estimation plus rapide du nombre d'allèles.

L'analyse des séquences des gènes $S$ chez les Solanacées $[64,65]$ et les Brassicacées [66, 67] a montré une très grande divergence entre les allèles fonctionnellement différents. Par exemple, chez Brassica oleracea et $B$. campestris, le nombre moyen de différences nucléotidiques entre deux allèles est de l'ordre de $10 \%$ pour les substitutions non synonymes, de $20 \%$ pour les substitutions synonymes et s'élève même à $25 \%$ (synonymes et non-synonymes) dans les régions hypervariables (voir plus loin). A titre de comparaison, le nombre moyen de différences nucléotidiques établi pour 214 gènes d'Arabidopsis thaliana n'est que de $0,6 \%$ (bien que le mode de calcul de cette valeur soit différent, il n'affecte pas l'ordre de grandeur). De plus, des allèles d'espèces différentes peuvent être plus semblables entre eux que ne le sont certains allèles d'une même espèce $[64,67,68]$. On parle alors de polymorphisme trans-spécifique (figure 4).

La grande divergence entre allèles et le polymorphisme partagé entre espèces peuvent tous deux s'expliquer par la grande ancienneté des allèles $S$. En effet, puisqu'un allèle est avantagé lorsqu'il devient rare, il peut difficilement être perdu par dérive génétique et les différents 


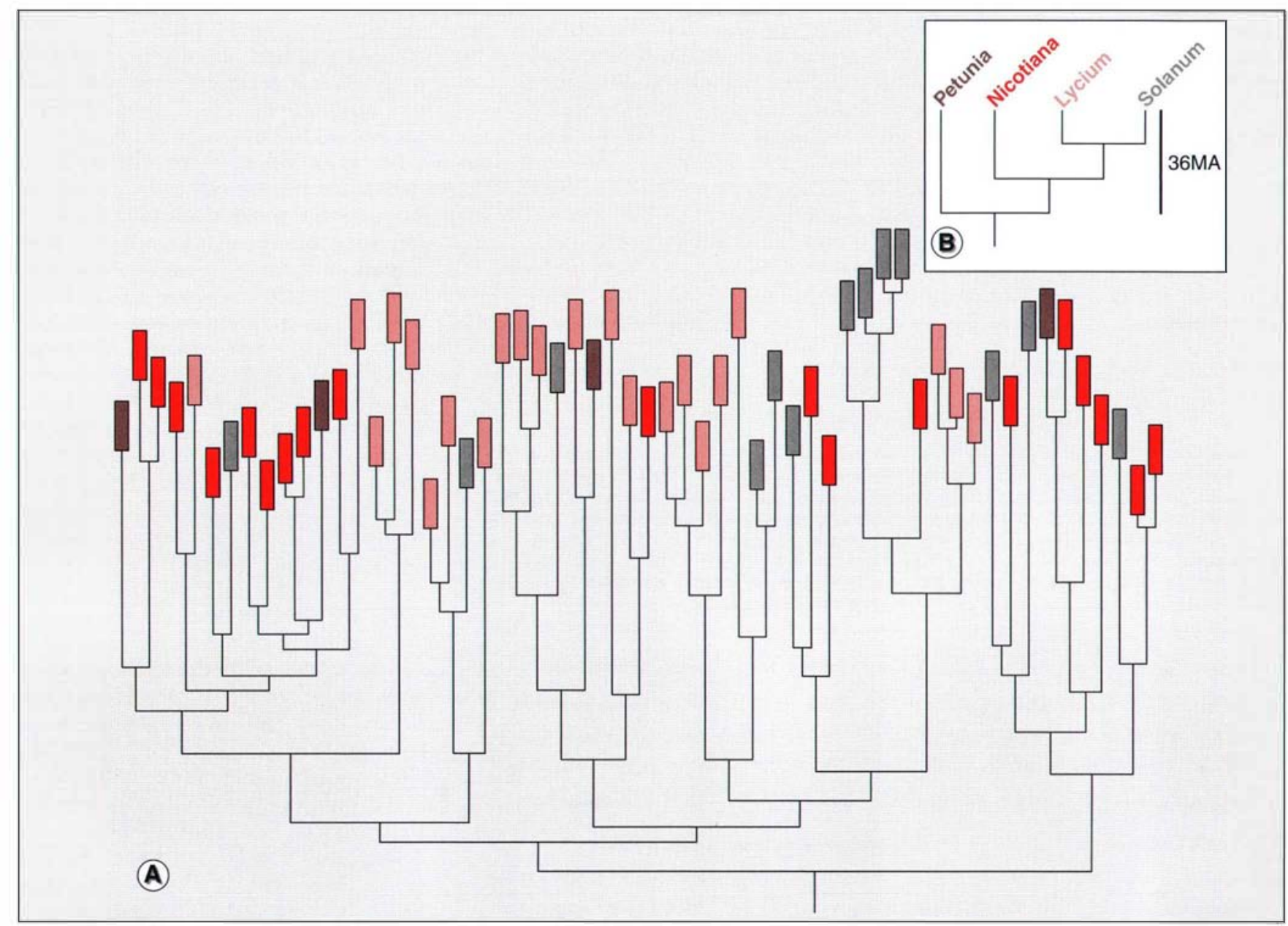

Figure 4. Polymorphisme trans-spécifique des allèles $\mathbf{S}$ chez différentes espèces de Solanacées. A. Phylogénie des allèles S. B. Phylogénie des espèces. Adapté de [81]. Les espèces présentées sont Petunia sp., Nicotiana alata, Solanum carolinense et Lycium andersonii. La phylogénie comparée des espèces et des allèles d'auto-incompatibilité montre clairement le polymorphisme trans-spécifique. Certains allèles sont plus proches d'allèles de la même espèce alors que d'autres sont plus proches d'allèles d'une autre espèce. II n'y a pas non plus de regroupements d'allèles entre deux espèces proches. La datation de la divergence entre les genres Petunia et Solanum à 36 millions souligne l'âge très élevé de certains allèles.

allèles vont donc être maintenus dans les populations pendant de très longues périodes évolutives [69]. De nombreuses mutations neutres (qui ne modifient pas la spécificité allélique) peuvent ainsi s'accumuler, entraînant des divergences de séquences très importantes. L'âge du dernier ancêtre commun à deux allèles peut alors être beaucoup plus important que l'âge de séparation de deux ou plusieurs espèces, ce qui explique le polymorphisme trans-spécifique. Il s'ensuit donc que si des contrer dans une même espèce, des allèles très semblables peuvent exister chez des espèces différentes. Chez les Solanacées, la divergence entre certains allèles remonte à plus de 40 millions d'années puisqu'elle a commencé avant la divergence entre les genres Petunia et Solanum qui est datée de 36 millions d'années (figure4) [64]. Chez les Brassicacées, le polymorphisme des allèles $S$ est estimé à environ 40 millions d'années alors qu'on évalue la diversification du genre Brassica à seulement 5 à 10 millions d'années [68].

\section{Régions hypervariables et sélection}

Le polymorphisme nucléotidique des allèles $S$ n'est pas réparti uniformément le long des séquences: il existe des régions hypervariables et des régions plus contraintes. Les régions hypervariables pourraient être les cibles de la sélection dépendante de la fréquence qui favorise les nouvelles spécificités alléliques et seraient dans ce cas impliquées dans les mécanismes de reconnaissance. Mais elles pourraient aussi être des régions faiblement contraintes, et 
donc fonctionnellement peu importantes. Un moyen de tester si ces régions sont soumises ou non à sélection est de comparer les taux de substitutions synonymes $\left(P_{\mathrm{s}}\right)$ aux taux de substitutions non synonymes $\left(P_{n}\right)$. Dans une région soumise à sélection diversifiante (comme la sélection dépendante de la fréquence), un excès de substitutions non synonymes par rapport aux substitutions synonymes $\left(P_{n} / P_{s}>1\right)$ est attendu puisque les changements d'acides aminés sont sélectionnés positivement. Un tel patron est effectivement observé chez les Solanacées [12] et les Rosacées [70] où l'on peut ainsi identifier les régions vraisemblablement impliquées dans les mécanismes de reconnaissance. Ces résultats sont concordants avec des expériences de transgenèse chez Solanum, mettant en évidence le rôle d'une région hypervariable dans la reconnaissance [18] bien que d'autres expériences aient pu donner des résultats différents [11]. Chez les Brassicacées en revanche, le rôle des régions hypervariables n'a pas été clairement établi [71]. Cependant, les études ont essentiellement porté sur le gène $S L G$ dont le rôle dans les mécanismes de reconnaissance a été remis en cause [40 et supra]. L'analyse du polymorphisme de séquence aurait pu apporter une réponse, mais le rapport $P_{n} / P_{s}$ n'est pas significativement différent de 1 , ce qui correspondrait à une évolution neutre de ces séquences [67]. Les régions hypervariables chez les Brassicacées pourraient donc être des régions faiblement contraintes, sans grande importance fonctionnelle. Cependant, l'action de la sélection n'est pas exclue. D'une part, pour des divergences entre séquences très anciennes (comme c'est le cas pour les allèles $S$ ), le rapport $P_{n} / P_{s}$ peut tendre vers 1 simplement à cause de la saturation des substitutions [72], même si les séquences sont soumises à sélection dépendante de la fréquence. D'autre part, il existe de forts déséquilibres de liaison au sein de ces régions vraisemblablement maintenu par sélection [72]. Chez les Brassicacées, il est donc difficile de conclure définitivement sur la nature

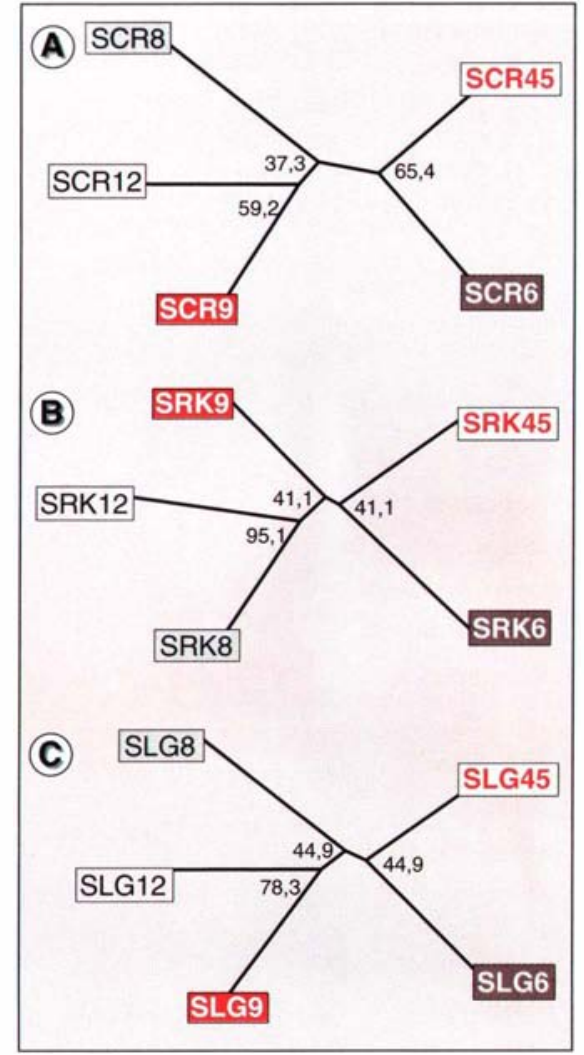

Figure 5. Phylogénie comparée des trois gènes, SCR (A), SRK (B) et SLG (C) pour cinq haplotypes S. Adapté de [51]. Les trois topologies sont relativement congruentes, mais ces phylogénies sont peu soutenues, en particulier pour le gène SCR, de petite taille et extrêmement polymorphe. Ces résultats ne sont donc pas définitifs, mais suggèrent une coévolution possible des gènes polliniques et des gènes stigmatiques.

des régions hypervariables. Il faut cependant souligner que toutes les séquences utilisées jusqu'à présent sont issues de différents cultivars et non d'individus de populations naturelles. Les contraintes sélectives ne sont donc pas nécessairement les mêmes. De plus, ces études de comparaison de séquences portent majoritairement sur le gène $S L G$. L'étude du polymorphisme de séquences du gène $S R K$ au sein de populations naturelles permettrait sans doute de mieux caractériser l'action de la sélection.
Coévolution des gènes du locus $S$ : le cas des Brassicacées

Chez les Brassicacées, nous avons vu que deux gènes, au moins, ont un rôle dans le fonctionnement de l'auto-incompatibilité: $S R K$, exprimé au niveau du stigmate et $S C R$, exprimé au niveau du pollen. L'implication d'un troisième gène, $S L G$, semble plus problématique (voir plus haut). Une question cruciale, et non encore résolue, est de savoir comment ces gènes peuvent coévoluer. Quelles informations apporte l'analyse des séquences de ces trois gènes? L'étude du domaine commun aux gènes $S L G$ et $S R K$, le domaine $S$, a mis en évidence, pour certains haplotypes, une évolution " concertée « de ces deux gènes. Dans ce cas, il existe une plus grande similitude de séquence entre les deux gènes différents au sein d'un même haplotype qu'entre deux allèles d'un même gène, ce qui implique l'existence de phénomènes de conversion entre les deux gènes [71]. Mais ce phénomène ne se retrouve pas pour tous les haplotypes. L'analyse phylogénétique de 20 haplotypes chez Brassica oleracea [40] montre que 7 couples $S L G / S R K$ sont effectivement regroupés, 4 sont au contraire bien séparés, et pour les 9 couples restants, les relations entre allèles ne permettent pas de conclure. Le gène $S C R$ n'a pas de domaine commun avec les gènes $S L G$ et $S R K$, mais la comparaison de la phylogénie de ses allèles avec celle des allèles de $S L G$ ou $S R K$, montre une certaine congruence des topologies (figure 5). Cependant, la petite taille du gène $S C R$ et la très grande divergence des allèles rendent difficile la construction de phylogénies robustes (voir les valeurs de bootstraps sur la figure 5A). Ces résultats encore partiels suggèrent une coévolution possible du gène pollinique avec les gènes stigmatiques, ce qui nécessite l'absence de recombinaison entre les différents gènes. En effet, tout événement de recombinaison entre les gènes stigmatiques et le gène pollinique conduirait à un haplotype non fonctionnel, probablement compatible. Du fait de réarrangements chromosomiques, la région du locus 


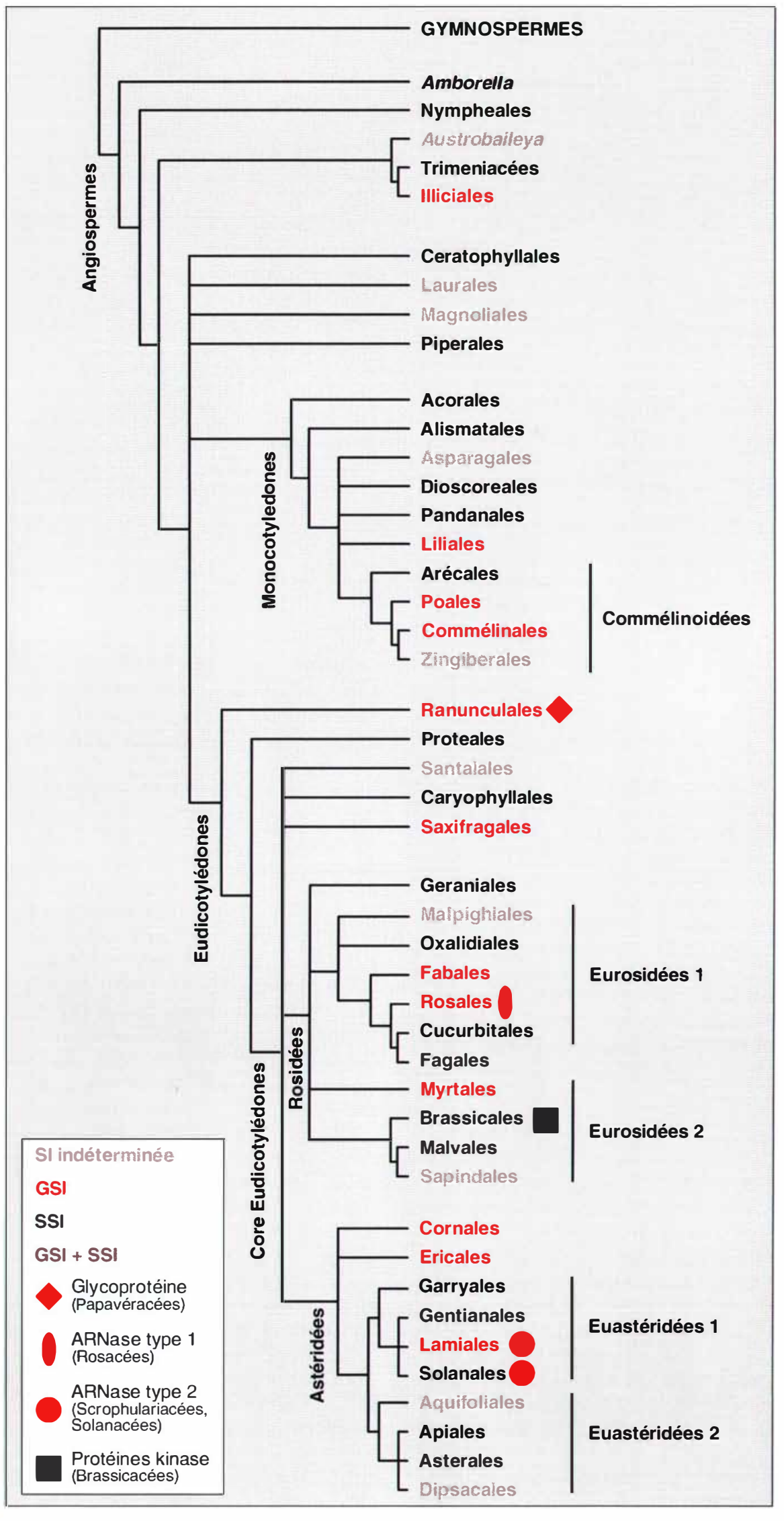

Figure 6. Systèmes d'auto-incompatibilité et phylogénie des Angiospermes. La phylogénie utilisée est la phylogénie consensuelle proposée par l'Angiosperm Phylogeny Group [77]. Les groupes où rien n'est indiqué correspondent à des groupes sans données fiables sur les systèmes d'auto-incompatibilité. Les systèmes d'auto-incompatibilité sont apparus très tôt dans l'histoire des Angiospermes même s'il semble que l'espèce de la base de l'arbre (Amborella) soit autocompatible. Les systèmes d'auto-incompatibilité sont également très répandus; on les trouve dans presque tous les ordres. Cependant, ils ont plusieurs origines différentes puisqu'il existe au moins quatre types de molécules. En supposant que les systèmes gamétophytiques sont apparus en premier, les systèmes sporophytiques ont alors au moins quatre origines différentes. 
$S$ est effectivement une région où la recombinaison est très réduite [73]. Cependant, au sein des gènes SLG et $S R K$, le déséquilibre de liaison décroît avec la distance physique, signature de l'existence d'événements de recombinaison intragénique au cours de l'histoire évolutive des allèles [72]. Ces événements de recombinaison intragénique pourraient conduire à la formation de nouveaux allèles mais l'apparition de nouvelles spécificités fonctionnelles reste problématique. En effet, la formation d'un nouvel haplotype fonctionnel nécessite au moins deux événements de mutation (mutation ponctuelle, recombinaison intragénique...) au sein d'un même haplotype de départ, voire trois si l'on considère que le gène $S L G$ est également nécessaire. Il s'agit donc d'événements très rares. Après une première mutation, par exemple sur le gène $\operatorname{SRK}\left(\mathrm{SRK}_{\mathrm{i}} \rightarrow \mathrm{SRK}_{\mathrm{j}}\right)$, il faut que l'haplotype incomplet généré (SRK $/$ $\mathrm{SCR}_{\mathrm{i}}$ ) persiste dans la population jusqu'à ce qu'une nouvelle mutation établisse complètement le nouvel haplotype $\left(\mathrm{SCR}_{\mathrm{i}} \rightarrow \mathrm{SCR}_{\mathrm{j}}\right)$. Les étapes intermédiaires sont donc décisives dans tout scénario évolutif qui se propose d'expliquer l'apparition de nouvelles spécificités. Cette question délicate est encore sujette à débat et le problème de l'évolution conjointe de deux gènes (un gène stigmatique et un gène pollinique) se pose également pour d'autres systèmes d'incompatibilité où l'on sait qu'il existe un gène pollinique [74-76].

\section{Origine et évolution des systèmes \\ d'auto-incompatibilité \\ chez les Angiospermes}

Les données moléculaires ont également permis d'aborder d'une façon nouvelle l'origine et l'évolution des systèmes d'auto-incompatibilité chez les Angiospermes, ce qui a conduit à des résultats très différents de la vision traditionnelle formulée initialement par Whitehouse (1951, d'après [68]). Pour cet auteur, l'origine des systèmes d'auto-incompatibilité est inséparable de l'origine des Angiospermes. Ces mécanismes d'évitement de l'autofécondation auraient constitué l'innovation évolutive clé, lors de la transition Gymnospermes/Angiospermes, qui aurait permis la radiation des Angiospermes à partir du Crétacé. Cette idée a été développée par la suite par plusieurs auteurs. L'incompatibilité serait donc apparue une seule fois sous forme gamétophytique, puis aurait, dans un premier temps, donné naissance à l'incompatibilité sporophytique par simple changement du moment d'expression des gènes $S$, et enfin aux systèmes d'incompatibilité hétéromorphiques (distylie, tristylie). Cette vision très progressiste, quasiment orthogénique, de l'évolution a été largement remise en cause par les données moléculaires sur les systèmes d'autoincompatibilité couplées aux récentes phylogénies moléculaires des Angiospermes [77]. Si les systèmes d'auto-incompatibilité semblent apparus très tôt chez les Angiospermes (ils sont déjà présents dans le groupe des Illiciales à la base de l'arbre, figure 6), leur apparition ne coïncide pas directement avec la diversification massive des Angiospermes qui correspond plutôt au passage des formes d'Angiospermes arbustives aux formes herbacées [78]. De plus, les molécules impliquées dans l'incompatibilité montrent clairement que ces systèmes sont apparus plusieurs fois indépendamment (figure 6). Ces molécules sont en effet très différentes : glycoprotéine chez les Papavéracées, RNase chez les Solanacées, Scrophulariacées et Rosacées et protéine kinase chez les Brassicacées. De plus, les RNases des Rosacées d'une part et des Solanacées et Scrophulariacées d'autre part sont d'origine différente et il s'agit dans ce cas d'une convergence évolutive [79]. De façon plus spéculative, si l'on considère que les systèmes gamétophytiques, qui sont largement les plus répandus, sont apparus en premier, les systèmes sporophytiques pourraient être apparus au moins quatre fois indépendamment: à la base des Eudicotylédones, au sein des Eurosidées I, des Eurosidées II et des Euastéridées (figure 6). L'auto-incompatibilité est largement répandue chez les Angiospermes, mais elle est apparue à plusieurs reprises et a également été perdue de nombreuses fois et même plusieurs fois au sein du genre Linanthus, Polemoniacées [80]. Ces systèmes semblent donc assez labiles et, au cours de l'évolution, différents mécanismes moléculaires d'évitement de l'autofécondation ont émergé.

En conclusion, la compréhension des mécanismes moléculaires impliqués dans l'auto-incompatibilité et de l'évolution de ces mécanismes est loin d'être complète. Mais, l'étude de ces systèmes constitue un très bon exemple d'interactions réciproques entre les approches moléculaires et cellulaires et les approches populationnelles et évolutives. L'étude du polymorphisme de séquences peut aider à déterminer le fonctionnement des protéines $S$ et les données moléculaires éclairent de façon nouvelle l'origine et l'évolution de ces systèmes

\section{RÉFÉRENCES}

1. Whitehouse HLK. Multiple-allelomorph incompatibility of pollen and style in the evolution of the angiosperms. Ann Bot $1950 ; 14: 198-216$.

2. De Nettancourt D, Incompatibility and incongruity in wild and cultivated plants, Springer, New York, Berlin, 2001, pp. 322.

3. Conner JA, Conner P, Nasrallah ME, Nasrallah JB. Comparative mapping of the Brassica $S$ locus region and its homeolog in Ara bidopsis. Implications for the evolution of mating systems in the Brassicaceae. Plant Cell 1998; 10: 801-12.

4. Kusaba M, Dwyer K, Hendershot J, Vrebalov J, Nasrallah JB, Nasrallah ME. Self-incompatibility in the genus Arabidopsis: characterization of the $S$ locus in the outcrossing $A$. lyrata and its autogamous relative A. thaliana. Plant Cell 2001 ; 13: 627-43.

5. Anderson MA, Cornish EC, Mau SI, et al. Cloning of cDNA for a stylar glycoprotein associated with expression of self-incompatibility in Nicotiana alata. Nature 1986; 321 : $38-44$.

6. McClure BA, Haring V, Ebert PR, et al. Style self-incompatibility gene products of Nicotiana alata are ribonucleases. Nature $1989 ; 342: 955-7$.

7. Tao R, Yamane H, Sassa H, et al. Identification of stylar RNases associated with gametophytic self-incompatibility in almond (Prunus dulcis). Plant Cell Physiol 1997; 38: 304-11. 


\section{RÉFÉRENCES}

8. Sassa $\mathbf{H}$, Nishio T, Kowyama Y, Hirano $\mathbf{H}$, Koba T, Ikehashi H. Self-incompatibility $(S)$ alleles of the Rosaceae encode members of a distinct class of the $\mathrm{T} 2 / \mathrm{S}$ ribonuclease superfamily. Mol Gen Genet 1996; 250: 547-57.

9. Ishimizu T, Shinkawa T, Sakiyama F, Norioka S. Primary structural features of rosaceous S-RNases associated with gametophytic self-incompatibility. Plant Mol Biol 1998; $37: 931-41$

10. Xue Y, Carpenter R, Dickinson HG, Coen ES. Origin of allelic diversity in Antirrhinum $S$ locus RNases. Plant Cell 1996; 8: 805-14.

11. Kao TH, McCubbin AG. How flowering plants discriminate between self and nonself pollen to prevent inbreeding. Proc Natl Acad Sci USA 1996; 93 : 12059-65.

12. Clark AG, Kao TH. Excess nonsynonymous substitution at shared polymorphic sites among self-incompatibility alleles of Solanaceae. Proc Natl Acad Sci USA 1991 ; 88 : 9823-7.

13. Newbigin E, Anderson MA, Clarke A. Gametophytic self-incompatibility systems. Plant Cell 1993; 5 : 1315-24.

14. Murfett J, Atherton T, Mou B, Gasser C, McClure B. S-RNase expressed in transgenic Nicoliana causes Sallele-specific pollen rejection. Nature 1994; 367:563-6.

15. Lee HS, Huang S, Kao TH. $S$ proteins control rejection of incompatible pollen in Petunia inflata. Nature 1994; 367: 560-3.

16. Huang S, Lee HS, Karunanandaa B, Kao T-H. Ribonuclease activity of Petunia inflata $S$ proteins is essential for rejection of self pollen. Plant Cell 1994; 6 : 1021-8.

17. Karunanandaa B, Huang $S$, Kao TH. Carbohydrate moiety of the Petunia inflata $S 3$ protein is not required for self-incompatibility interactions between pollen and pistil. Plant Cell 1994 ; 6 : 1933-40.

18. Matton DP, Maes O, Laublin G, et al. Hy pervariable domains of self-incompatibility RNases mediate allele-specific pollen recognition. Plant Cell 1997; 9: 1757-66.

19. Verica JA, McCubbin AG, Kao, TH. Are the hypervariable regions of $S$ RNases sufficient for allele-specific recognition of pollen? Plant Cell 1998; 10 : 314-6.

20. Luu DT, Qin X, Morse D, Cappadocia M. S-RNase uptake by compatible pollen tubes in gametophytic self-incompatibility. Nature 2000; 407:649-51.

21. Foote HCC, Ride JP, Franklin-Tong VE, Walker EA, Lawrence MJ, Franklin FCH. Cloning and expression of a novel self-incompatibility ( $S$-) gene from Papaver rhoeas
22. Hearn MJ, Franklin CH, Ride JP. Identification of a membrane glycoprotein in pollen of Papaver rhoeas which binds stigmatic self-incompatibility $(S-)$ proteins. Plant $J$ $1996 ; 9: 467-75$

23. Rudd JJ, Franklin FCH, Franklin-Tong VE. $\mathrm{Ca}^{2+}$-independent phosphorylation of a $68 \mathrm{kDa}$ pollen protein is stimulated by the self-incompatibility response in Papaver rhoeas. Plant J 1997; 12:507-14.

24. Clarke SR, Staiger CJ, Gibbon BC, Franklin-Tong VE. $\AA$ potential signaling role for profilin in pollen of Papaver rhoeas. Plant Cell 1998; 10: 967-79.

25. Bateman AJ. Self-incompatibility systems in angiosperms. III. Cruciferae. Heredity 1955 ; $9: 52-68$.

26. Boyes DC, Nasrallah ME, Vrebalov J, Nasrallah JB. The self-incompatibility $(S)$ haplotypes of Brassica contain highly divergent and rearranged sequences of ancient origin. Plant Cell 1997; 9: 237-47.

27. Yu K, Schafer U, Glavin TL, Goring DR, Rothstein SJ. Molecular characterization of the $S$ locus in two self-incompatible Brassica napus lines. Plant Cell 1996; 8: 2369-80.

28. Cui Y, Brugiere N, Jackman L, Bi YM, Rothstein SJ. Structural and transcriptional comparative analysis of the $S$ locus regions in two self-incompatible Brassica napus lines. Plant Cell 1999; 11: 2217-31.

29. Suzuki G, Kai N, Hirose T, et al. Genomic organization of the $S$ locus: Identification and characterization of genes in SLG/SRK region of $S_{4}$ haplotype of Brassica campestris (syn. rapa), Genetics 1999; 153: 391-400.

30. Boyes DC, Nasrallah JB. Physical linkage of the $S L G$ and $S R K$ genes at the self-incompatibility locus of Brassica oleracea. Mol Gen Genet 1993; 236 : 369-73.

31. Nasrallah JB, Kao TH, Goldberg ML, Nasrallah ME. A cDNA clone encoding an Slocus specific glvcoprotein from Brassica oleracea. Nature 1985 ; 318 : 617-8.

32. Stein JC, Howlett B, Boyes DC, Nasrallah ME, Nasrallah JB. Molecular cloning of a putative receptor protein kinase gene encoded at the self-incompatibility locus of Brassica oleracea. Proc Natl Acad Sci USA 1991 ; 88 : 8816-20.

33. Schopfer CR, Nasrallah ME, Nasrallah JB. The male determinant of self-incompatibility in Brassica. Science 1999; 286: 1697 . 700 .

34. Stein JC, Dixit R, Nasrallah ME, Nasrallah JB. $S R K$, the stigma-specific $S$ locus receptor kinase of Brassica, is targeted to the plasma membrane in transgenic tobacco. Plant Cell 1996; 8: 429-45.

35. Tantikanjana T, Nasrallah ME, Stein JC, Chen CH, Nasrallah JB. An alternative transcript of the $S$ locus glycoprotein gene in a class II pollen-recessive self-incompati- bility haplotype of Brassica oleracea encodes a membrane-anchored protein. Plant Cel $1993 ; 5: 657-66$.

36. Cabrillac D, Delorme V, Garin J, et al. The $S_{t 5}$ self-incompatibility haplotype in Brassica oleracea includes three $S$ gene family members expressed in stigmas, Plant Cell $1999 ; 11$ : 971-86.

37. Gaude T, Friry A, Heizmann P, et al. Expression of a self-incompatibility gene in a self-compatible line of Brassica oleracea. Plant Cell 1993; $5:$ 75-86.

38. Gaude T, Rougier M, Heizmann P, Ockendon DJ, Dumas C. Expression level of the $S L G$ gene is not correlated with the selfincompatibility phenotype in the class II $S$ haplotypes of Brassica oleracea. Plant Mol Biol $1995 ; 27: 1003-14$

39. Okazaki K, Kusaba M, Ockendon DJ, Nishio T. Characterization of $S$ tester lines in Brassica oleracea: polvmorphisms of restriction fragment length of SLG homologues and isoelectric points of Slocus glycoproteins. Theor Appl Genet 1999; 98: 1329-34.

40. Nishio T, Kusaba M. Sequence diversity of $S L G$ and SRK in Brassica oleracea L. Ann Bot $2000 ; 85$ : 141-6.

41. Goring DR, Rothstein SJ. The Slocus receptor kinase gene in a self-incompatible Brassica napus line encodes a functional serine/threonine kinase. Plant Cell 1992; 4: 1273-81.

42. Stein JC, Nasrallah JB. A plant receptorlike gene, the Slocus receptor kinase of Brassica oleracea $\mathrm{L}_{\text {., }}$ encodes a functional serine/threonine kinase. Plant Physiol 1993; 101: 1103-6.

43. Giranton JL, Dumas C, Cock JM, Gaude T. The integral membrane $S$-locus receptor kinase of Brassica has serine/threonine kinase activity in a membranous environment and spontaneously forms oligomers in planta. Proc Natl Acad Sci USA 2000; 97 : 3759-64

44. Goring DR, Glavin TL, Schafer U, Rothstein SJ. An $S$ receptor kinase gene in selfcompatible Brassica napus has a 1-bp deletion. Plant Cell 1993 ; 5 : 531-9.

45. Nasrallah JB, Rundle SJ, Nasrallah ME. Genetic evidence for the requirement of the Brassica Slocus receptor kinase gene in the self-incompatibility response. Plant $1994 ; 5: 373-84$

46. Takasaki T, Hatakeyama K, Suzuki G, Watanabe $M$, Isogai A, Hinata $\mathrm{K}$. The $S$ re ceptor kinase determines self-incompatibility in Brassica stigma. Nature $2000 ; 403: 913$ 6.

47. Boyes DC, Nasrallah JB. An anther-specific gene encoded by an $S$ locus haplotype of Brassica produces complementary and differentially regulated transcripts. Plant Cell $1995 ; 7: 1283-94$ 


\section{Société Française de Génétique}

\section{RÉFÉRENCES}

48. Pastuglia M, Ruffio-Chable V, Delorme V, Gaude T, Dumas C, Cock JM. A functional $S$ locus anther gene is not required for the self-incompatibility response in Brassica oleracea. Plant Cell 1997; 9 : 2065-76.

49. Miege C, Dumas C, Cock IM. Identification of a gene linked to the Brassica $S$ (selfincompatibility) locus by differential display. C R Acad Sci 1999; 322: 1051-60.

50. Stephenson AG, Doughty J, Dixon S, Elleman $\mathrm{C}$, Hiscock S, Dickinson HG. The male determinant of self-incompatibility in Brassica oleracea is located in the pollen coating. Plant J 1997; 12: 1351-9.

51. Watanabe M, Ito A, Takada $\mathrm{Y}$, et al. Highly divergent sequences of the pollen self-incompatibility $(S)$ gene in class-l $S$ haplotypes of Brassica campestris (syn. rapa) L. FEBS Letters $2000 ; 473$ : 139-44.

52. Takayama S, Shiba $\mathrm{H}$, Iwano $\mathrm{M}$, et al. The pollen determinant of self-incompatibility in Brassica campestris. Proc Natl Acad Sci USA $2000 ; 97:$ 1920-5.

53. Giranton JL, Ariza MJ, Dumas C, Cock JM, Gaude T. The $S$ locus receptor kinase gene encodes a soluble glycoprotein corresponding to the SKR extracellular domain in Brassica oleracea. Plant J 1995; 8: 827-34.

54. Duan DS, Pazin MJ, Fretto LJ, Williams LT. A functional soluble extracellular region of the platelet-derived growth factor (PDGF) beta-receptor antagonizes PDGF-stimulated responses. J Biol Chem 1991; 266 : 413-8.

55. Flickinger TW, Maihle NI, Kung HJ. An alternatively processed mRNA from the avian c-erbB gene encodes a soluble, truncated form of the receptor that can block ligand-dependent transformation. Mol Cell Biol 1992; 12: 883-93.

56. Heldin CH. Dimerization of cell surface receptors in signal transduction. Cell 1995; $80: 213-23$.

57. Cabrillac D, Cock JM, Dumas C, Gaude $\mathrm{T}$. The $S$ locus receptor kinase is inhibited by thioredoxins and activated by pollen coat proteins. Nature $2001 ; 410: 220-3$.
58. Wang T, Li BY, Danielson PD, et al. The immunophilin FKBP12 functions as a common inhibitor of the TGF beta family type I receptors. Cell 1996; 86: 435-44.

59. Lopez-Ilasaca M, Schiene C, Kullertz G, Tradler T, Fischer G, Wetzker R. Effects of FK506-binding protein $\mathbf{1 2}$ and FK506 on autophosphorylation of epidermal growth fac tor receptor, J Biol Chem 1998; 273: 9430-4.

60. Gu T, Mazzurco M, Sulaman W, Matias DD, Goring DR. Binding of an arm repeat protein to the kinase domain of the Slocus receptor kinase. Proc Natl Acad Sci USA $1998 ; 95: 382-7$

61. Stone SL, Arnoldo M, Goring DR. A breakdown of Brassica self-incompatibility in $A R C 1$ antisense transgenic plants. Science 1999 ; 286 : 1729-31.

62. Lawrence MJ. Population genetics of the homomorphic self-incompatibility polymorphisms in flowering plants. Ann Bot 2000 85 (suppl A) : 221-6.

63. Wright $\mathrm{S}$. The distribution of self-sterility alleles in populations. Genetics $1939 ; 24$ 538-52.

64. Ioerger TR, Clark AG, Kao TH. Polymorphism at the self-incompatibility locus in Solanaceae predates speciation. Proc Nall Acad Sci USA 1990; 87: 9732-5.

65. Richman AD, Uyenoyama MK, Kohn JR. Allelic diversity and gene genealogy at the self-incompatibility locus in the Solanaceae. Science 1996; 273: 1212-6.

66. Nasrallah JB. Evolution of the Brassica self-incompatibility locus: a look into Slocus gene polymorphisms. Proc Natl Acad Sci USA 1997; 94 : $9516-9$.

67. Charlesworth D, Awadalla P. Flowering plant self-incompatibility: the molecular population genetics of Brassica S-loci. Heredity 1998; $81: 1-9$.

68. Uyenoyama MK A generalized leastsquares estimate for the origin of sporophy tic self-incompatibility. Genetics 1995; 139 : 975-92.

69. Vekemans X, Slatkin M. Gene and allelic genealogies at a gametophytic self-incompatibility locus. Genetics 1994; 137: $1157-65$.

70. Ishimizu T, Endo T, Yamaguchi-Kabata Y, Nakamura KT, Sakiyama F, Norioka S
Identification of regions in which positive selection may operate in S-RNase of Rosaceae: implication for S-allele-specific recognition sites in S-RNase. FEBS Letters 1998; $440: 337-42$

71. Kusaba M, Nishio T, Satta Y, Hinata K, Ockendon D. Striking sequence similarity in inter- and intra-specific comparisons of class I SLG alleles from Brassica oleracea and Brassica campestris: implications for the evolution and recognition mechanism. Proc Natl Acad Sci USA 1997; 94 : 7673-8.

72. Awadalla P, Charlesworth D. Recombination and selection at Brassica self-incompatibility loci. Genetics 1999; 152:413-25.

73. Boyes, Nasrallah ME, Vrebalov J, Nasrallah JB. Self-incompatibility (S) haplotypes of Brassica contain divergent and rearranged sequences of ancient origin. The Plant Cell 1997; 9: 237-47.

74. Charlesworth D. How can two-gene models of self-incompatibility generate new specificities. The Plant Cell 2000; 12 : 309-10.

75. Uyenoyama MK, Newbigin E. Evolutionary dynamics of dual-specificity self-incompatibility alleles. The Plant Cell 2000; 12: 310-2.

76. Matton DP, Luu DT, Morse D. Reply: establishing a paradigm for the generation of new $S$ alleles. The Plant Cell 2000; $12: 313-5$.

77. Soltis PS, Soltis DE, Chase MW. Angiosperm phylogeny inferred from multiple genes as a tool for comparative biology. $\mathrm{Na}$ ture $1999 ; 402$ : 402-4.

78. Mathews S, Donoghue MJ. The root of Angiosperm phylogeny inferred from duplicate phytochrome genes. Science $1999 ; 286$ : 947-50.

79. Richman AD, Broothaerts W, Kohn JR. Self-incompatibility RNases from three plant families: homology or convergence. Am J Bot 1997; 84 : 912-7.

80. Goodwillie C. Multiple origins of selfcompatibility in Linanthus section Leptosiphon (Polemoniaceae): phylogenetic evidence from internal-transcribed-spacer sequence data. Evolution 1999; 53: 1387-95.

81. Richman AD. Sallele diversity in Lycium andersomii: implications for the evolution of Sallele age in the Solanaceae. Ann Bot 2000; 85 (suppl A) : 241-5. 


\section{Summary}

Self-incompatibility in flowering plants

During the course of evolution, recognition mechanisms that prevent self-fertilization in flowering plants have been selected. These mechanisms, named self-incompatibility, allow self-pollen rejection by the pistil. In most cases, the selfincompatibility response is under the genetic control of a single multiallelic locus, the $S$ (Self-incompatibility) locus. Depending on the genetic control of the self-pollen rejection, two major classes of selfincompatibility systems have been described. The most common systems correspond to the gametophytic self-incompatibility, which has been well characterized in the Solanaceae and in the Papaveraceae. The second type of self-incompatibility systems corresponds to the sporo- phytic self-incompatibility, particularly well studied in the Brassicaceae. In the review article, we present recent advances in understanding the molecular events that lead to pollen recognition and rejection in both systems. Interestingly, different molecules and signaling pathways have been recruited during evolution of flowering plants to answer the same biological question: how to discriminate male partners and to efficiently prevent self-fertilization by the pistil of hermaphroditic flowers ? The origin and molecular evolution of these multiallelic systems is discussed.

\section{TIRÉS À PART}

T. Gaude.

\section{Gaude Thierry \\ Didier Cabrillac}

Reproduction et développement des plantes, École normale supérieure de Lyon, UMR 5667 CNRS-INRA-ENSLUCB Lyon, 46, allée d'Italie, 69364 Lyon Cedex 07, France.

\section{Sylvain Glémin}

Institut des sciences de l'évolution, station d'amélioration des plantes INRA, Laboratoire génétique et environnement, Université Montpellier 2, place EugèneBataillon, 34095 Montpellier Cedex 05, France et Station d'amélioration des Plantes INRA; Domaine de Melgueil, 34130 Mauguio, France.

\section{Agnès Mignot}

Institut des sciences de l'évolution, Station d'amélioration des plantes INRA, Laboratoire génétique et environnement, Université Montpellier 2, place Eugène-Bataillon, 34095 Montpellier Cedex 05, France. 